\title{
Optimization of germination process of "Cam" brown rice by response surface methodology and evaluation of germinated rice quality
}

\author{
1, ${ }^{*}$ Loan, L.T.K. and ${ }^{2}$ Thuy, N.M. \\ ${ }^{1}$ Faculty of Agriculture and Food Technology, Tien Giang University, Vietnam \\ ${ }^{2}$ College of Agriculture, Can Tho University, Vietnam
}

\begin{abstract}
Article history:
Received: 1 September 2019 Received in revised form: 16 October 2019

Accepted: 19 October 2019

Available Online: 28 October 2019
\end{abstract}

\section{Keywords:}

Anthocyanins,

Germinated "Cam" brown

rice,

Germination,

Optimization,

Soaking

\begin{abstract}
"Cam" brown rice (CBR), a Vietnamese cultivar containing a high level of anthocyanin was germinated at various conditions to maximize anthocyanin. To obtain optimum conditions, major factors such as soaking time, $\mathrm{pH}$, germination time and temperature were evaluated using Box-Behnken design to achieve the highest anthocyanin content in germinated "Cam" brown rice (GCBR). The results revealed that $2.6 \mathrm{hrs}$ of soaking at $\mathrm{pH}$ 3.1 and followed by $15.5 \mathrm{hrs}$ of germination were optimal germination condition to achieve maximum anthocyanin content $(45.18 \mathrm{mg} / 100 \mathrm{~g}$ GCBR). Along with high content of anthocyanin, the increased amounts of these nutrients relative to those in the un-GCBR were 7 times for GABA, 17\% polyphenol and 22\% reducing sugars. In addition, GCBR possessed good sensory characteristics in structure and taste.
\end{abstract}

DOI:

https://doi.org/10.26656/fr.2017.4(2).307.1

\section{Introduction}

Rice (Oryza sativa L.) is one of the important food crops feeding over $50 \%$ of the world's population, particularly in Asia (Thuengtung et al., 2018). Compared to white or polished rice, brown rice is an excellent source of nutrients that have potential functional food benefits such as dietary fibers, vitamins, gamma-amino butyric acid (GABA) and gamma-oryzanol (Wu et al., 2013). In spite of its nutritional value and health benefits, brown rice is not widely consumed because of its poor cooking properties and hard texture due to high fiber content present in the bran (Moongngarm and Saetung, 2010). Several studies have shown that the functional and nutritional properties of brown rice can be improved through the process of germination (Kaur et al., 2017). Meanwhile, germinated brown rice (GBR) is increasingly gaining attention, especially in Asian countries, owing to its improved eating quality and potential health-promoting functions (Sangsila et al., 2018). GBR is evaluated as a functional food because it is good in digestion and absorption. Dried GBR offers an excellent appearance, improved shelf life and handling ease. GBR frees its bound minerals by reducing phytic acid content, making them more absorb into the body (Kim et al., 2012). Unlike white rice, GBR provides more sweetness, excellent taste, has better texture and is easier to cook (You-Tung et al., 2015). In a germination process, rice has been softened during the steeping stage, which will be soft enough to eat when cooked in an ordinary rice cooker (Sutharut and Sudarat, 2012). Many nutrients such as vitamin B, reducing sugar, and total protein contents of GBR were increased and higher than those of ungerminated brown rice (Trachoo et al., 2006). The consumption of germinated brown rice is being associated with improvement in human health due to wide range of biological properties such as anti-bacterial, anti-viral, anti-inflammatory and anti-allergic present in phenolics (Sutharut and Sudarat, 2012).

"Cam" rice was grown at Cai Lay district of Tien Giang province, Viet Nam. "Cam" rice contains more vitamins, protein, minerals, dietary fiber and anthocyanin, compared to those of other rice cultivars (Loan and Thuy, 2019). Anthocyanins are water-soluble pigments belonging to the phenolic group that have high antioxidant activities. Colors in the rice are due to the deposition of large amounts of anthocyanin pigment in the rice coat (Chaudhary, 2003). Anthocyanin has been recognized as health-promoting functional food ingredients due to their antioxidant activity (Nam et al., 2006), anticancer (Zhao et al., 2004), hypoglycemic, anti -inflammatory effects (Tsuda et al., 2002), and these functions provide synergic effects with various nutrients in vivo (Kim et al., 2008). The antioxidants are crucial for memory enhancement and strengthening of the immune system (Pengkumsri et al., 2015). The prevention of cancer-cell invasion property of peonidin, 
peonidin 3-glucoside, cyanidin 3-glucoside, and other major anthocyanins of rice has been reported by Chen et al. (2006). Choi et al. (2006) reported that the pigments of colored rice bran inhibit allergic reactions in vitro.

Box-Behnken design is a widely acceptable response surface methodology (RSM) to detect the optimum conditions for the desired outcome with optimal values of selected influencing variables (Chaiyasut et al., 2017). Thus, this study examined the effect of soaking time and $\mathrm{pH}$ of the water, germination time and temperature on the anthocyanin content of GBR, using Box-Behnken design. The alterations in the nutritional components of GBR germinated at optimum condition were also investigated.

\section{Materials and methods}

\subsection{Rice sample and germination process}

CBR composition was expressed as dried basis: $9.8 \%$ protein, $12.8 \%$ moisture and $66.4 \mathrm{mg}$ anthocyanin/100 g (Loan et al., 2018). The paddies were milled in Satake miller, packed in polyamide bags, and then kept at $4^{\circ} \mathrm{C}$ throughout the experiment. Rice samples $(200 \mathrm{~g})$ were thoroughly cleaned and defective grains were excluded. Then, CBR was steeped in distilled water (water: grain ratio $=2: 1$ ), at ambient temperature for 2, 3 and $4 \mathrm{hrs}$ and $\mathrm{pH} \mathrm{2,3}$ and 4 . Following 12, 16 and $20 \mathrm{hrs}$ germination at $32.5^{\circ} \mathrm{C}, 35^{\circ} \mathrm{C}$ and $37.5^{\circ} \mathrm{C}$ temperature. The steeped rice was left to germinate in an incubator for the specified durations. The germinated "Cam" brown rice (GCBR) was dried to get moisture content lower than $13 \%$ using a tray dryer at $50^{\circ} \mathrm{C}$ to preserve enzyme activities, anthocyanin content and nutritional components were analyzed.

\subsection{Methods}

Box-Behnken experimental design with four factors on three levels was used. In this work, independent variables used in experimental design were the amount of soaking time and $\mathrm{pH}$ of the water, germination time and temperature. The design consisted of 81 runs with three replicates of the center point with three blocks. The order of the experiments had been fully randomized. The experimental data were established by quadratic model.

\subsection{Chemical analyses}

\subsubsection{Determination of anthocyanin content}

The total anthocyanin content was determined according to the spectrophotometric $\mathrm{pH}$ differential method (Lee et al., 2005). Briefly, an aliquot $(0.3 \mathrm{~mL})$ of anthocyanin sample was mixed with $\mathrm{pH} 1.0$ (potassium chloride buffer, $9.7 \mathrm{~mL}$ ) and $\mathrm{pH} 4.5$ (sodium acetate buffer, $9.7 \mathrm{~mL}$ ) solutions, respectively, and equilibrated for $30 \mathrm{~min}$ at room temperature in the dark. The absorbance of the mixture was measured at 525 and 700 $\mathrm{nm}$ using a UV-Vis spectrophotometer. The total anthocyanin content was calculated as cyanidin-3glucoside equivalents as in the following equation:

$$
\text { Anthocyanin content }(\mathrm{mg} / 100 \mathrm{~g})=\frac{\mathrm{A} \times \mathrm{M}_{\mathrm{W}} \times \mathrm{D}_{\mathrm{F}} \times \mathrm{V} \times 100}{\varepsilon \times \mathrm{l}}
$$

Where $\left.\mathrm{A}=\left[\mathrm{A}_{525}-\mathrm{A}_{700}\right) \mathrm{pH}_{1.0}\right]-\left[\left(\mathrm{A}_{525}-\mathrm{A}_{700}\right) \mathrm{pH}_{4.5}\right] ; \mathrm{M}_{\mathrm{w}}$ is the molecular weight of cyanidin-3-glucoside $(449.2 \mathrm{~g} /$ $\mathrm{mol}) ; \mathrm{D}_{\mathrm{F}}$ is the dilution factor; $\mathrm{V}$ is the volume of the extract $(\mathrm{mL}) ; \varepsilon$ is the molar extinction coefficient $(26,900)$ of cyanindin-3-glucoside; and 1 is the cell path length $(1 \mathrm{~cm})$.

\subsubsection{Determination of nutritional components}

$\gamma$ - aminobutyric acid (GABA) was determined by the method of Banchuen et al. (2010). Ground germinated brown rice samples of one-fifth to one-half gram $(0.2-0.5 \mathrm{~g})$ were weighed in plastic tubes and 1.8 $\mathrm{mL}$ of deionized water was added and the slurries were shaken at room temperature. Thereafter, $200 \mathrm{~mL}$ of $3 \%$ (by volume) sulfosalicylic acid was added and the mixtures were centrifuged at $4500 \mathrm{x} g$ for 10 mins. To 50 $\mathrm{mL}$ of the supernatants were added $50 \mathrm{~mL}$ of $100 \mathrm{mM}$ $\begin{array}{lllllll}\mathrm{NaHCO}_{3} & \text { and } & 50 & \mathrm{~mL} & \text { of } & 4 & \mathrm{mM}\end{array}$ dimethylaminoazobenzene-4-sulfonyl chloride acetonitrile solutions. The mixtures were heated to $70^{\circ} \mathrm{C}$ for $10 \mathrm{mins}$ to effect derivatization. After the derivatization, the samples were added $250 \mathrm{~mL}$ of absolute ethanol and $250 \mathrm{~mL}$ of $25 \mathrm{mM}$ phosphate buffer (pH 6.8). The samples were then filtered, and $5 \mathrm{~mL}$ of the filtrate was injected into HPLC. The HPLC was equipped with a UV-Vis photodiode array detector set at $465 \mathrm{~nm}$ wavelength.

Total polyphenol was determined by FolinCiocalteau method (Pengkumsri et al., 2015). A total of $100 \mu \mathrm{L}$ of Folin-Ciocalteu reagent was mixed with 1.5 $\mathrm{mL}$ of deionized water and $200 \mu \mathrm{L}$ of extracts or gallic acid (positive control) with different concentrations. Then, the reaction was neutralized with $20 \%$ saturated sodium carbonate. The absorbance was measured at 725 $\mathrm{nm}$ after $30 \mathrm{~min}$ incubation at room temperature. Total phenolic content was denoted as $\mathrm{mg}$ of gallic acid equivalent (mg GAE) per $g$ of extract.

The moisture content of rice samples in wet basis (w.b.) was determined by drying them in an oven at $105^{\circ}$ C to constant weight, according to AOAC (2010). The total lipid content was determined using the Soxhlet method (Soxhlet, 1879). The total protein content was determined using the Kjeldahl method (AOAC, 2010). The total and reducing sugars were determined following 
the methods by Holm et al. (1986) and Somogyi (1952) respectively.

\subsection{Quantitative descriptive analysis}

Quantitative descriptive analysis (QDA) was carried out by a group of eleven panelists. A group of sensory analysis panels was made of male and female who have been selected and trained to perform sensory tasks. QDA used a five-point scale ranging from good to bad. CBR and GCBR were used the same the water ratio and cooked with the same temperature, time. Panelists were instructed to visually evaluate for color and aroma, then take at least one a half of cafe spoon of rice, and slowly masticate the product before providing acceptability taste and texture.

\subsection{Statistical analysis}

The optimum levels of the factors in germination process of CBR were determined with RSM. The germination of brown rice was prepared according to the experimental design in order to achieve high anthocyanin by using Statgraphics Centurion XVI. The data obtained were statistically treated by analysis of variance (ANOVA) and the means were compared by the LSD test at a significance level of 0.05 . The experimental data were established by quadratic model. Optimum parameters were defined by the Design-Expert software. The nutritional components and sensory quality were performed in independent triplicates data are reported as mean $\pm \mathrm{SD}$. Data were presented as mean of sample sets. Statistical analysis of the results to assess significant differences among samples was performed.

\section{Results and discussion}

\subsection{Optimum condition for anthocyanin content}

The present study emphasized on the enhancement of anthocyanin content of CBR by germination. It is known that main factors influence the anthocyanin formation in germinated rice, particularly, soaking time, soaking $\mathrm{pH}$, germination time and temperature (Loan and Thuy, 2019).

The Box-Behnken design was employed for the detection of optimum condition for anthocyanin content. Three levels of soaking times (2, 3, and $4 \mathrm{hrs})$, soaking water $\mathrm{pH}(2,3,4)$, germination time $(12,16,20 \mathrm{hrs})$, and germination temperature $\left(32.5^{\circ} \mathrm{C}, 35^{\circ} \mathrm{C}, 37.5^{\circ} \mathrm{C}\right)$ were set up and twenty-seven independent experiments were performed. The influences of soaking and germination conditions on anthocyanin content of GBR were shown in Figure 1.
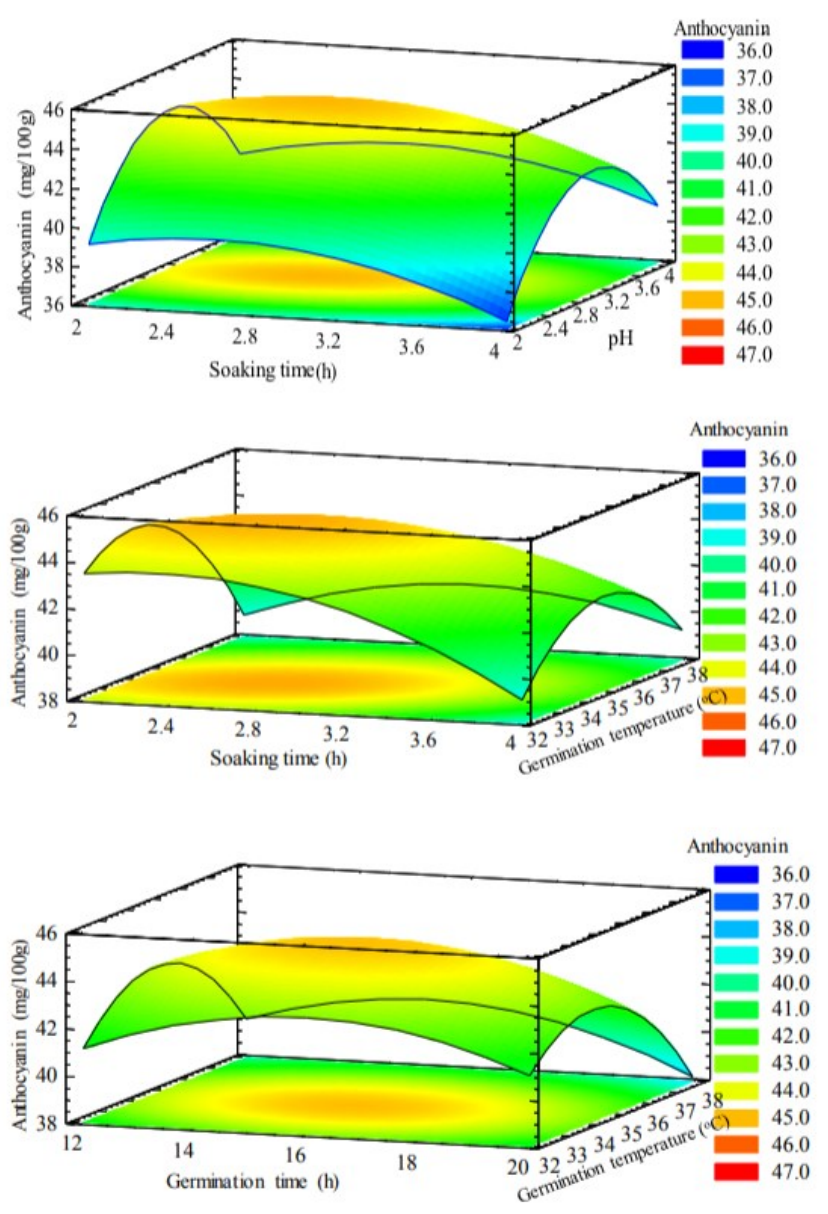


Figure 1. Response surface and contour plots for the effects on anthocyanin of soaking time and $\mathrm{pH}$, germination time and temperature 
From Figure 2, it is confirmed that all the factors were in effect on anthocyanin contents of GCBR. The effect of factors indicated that a medium concentration of each factor was nearly optimum levels. The low or high concentration of this variable made slow anthocyanin content. Anthocyanins are less stable in various environmental conditions. The stability of anthocyanin is influenced by several factors such as $\mathrm{pH}$, temperature, oxygen, light, concentration, the presence of copigments, metallic ions and enzymes (Roobha et al., 2011). Anthocyanins have four different structures. The relative amounts of these structures in equilibrium are varied and depend on the $\mathrm{pH}$ and anthocyanin structure (Roobha et al., 2011). This is because of the molecular structure of anthocyanin having an ionic nature (Turturică et al., 2015). Most of the anthocyanin pigments have a high stability in acidic conditions compared with bases, and degradation occurs at higher pHs (Khoo et al., 2017).



Figure 2. Main effect plot for anthocyanin

The losses of total anthocyanin content of brown rice were greater when soaked at $\mathrm{pH} 2$ and 4 than at $\mathrm{pH} 3$. Besides, pH 2 could make GCBR taste more sour than other soaking pHs. It is important to notice that soaking at $\mathrm{pH} 3$ is suitable for germination of CBR.

Temperature is another notable factor that could influence the stability of anthocyanin content. It is well known that anthocyanins are readily degraded when exposed to heat, resulting in a dramatic impact on color and their health-promoting properties (Harakotr et al., 2014). The high losses of anthocyanin content when subjected to high temperature for long time might be attributed to thermal degradation of anthocyanin compounds. The significant losses of anthocyanin during germination might be due to the thermal degradation of anthocyanin involving hydrolysis of glycoside linkages to form chalcone or $\alpha$-diketone. These results suggested the decrease of anthocyanin at $37.5^{\circ} \mathrm{C}$ can be predominantly rather than at 32.5 and $35^{\circ} \mathrm{C}$. The rate of anthocyanin degradation by heating increased because of reacting molecules when the extract is concentrated (Kirca et al., 2007). Anthocyanins are water-soluble pigments belonging to the phenolic group that have high antioxidant activities (Khoo et al., 2017). These significant losses could be attributed to water-soluble anthocyanin components leaching into soaking water as well as breakdown of anthocyanin components to contact oxy for a long time. Samples soaked for 2 or $3 \mathrm{hrs}$ showed higher anthocyanin content than samples soaked for $4 \mathrm{hrs}$.

The germination time of rice plays a critical role in the therapeutic property of germinated rice since it increases the bioactive compounds (Chaiyasut et al., 2017). During the sprouting process, enzyme activities will increase so there will be changes in nutrition and secondary metabolism compounds, such as anthocyanin (Umnajkitikorn et al., 2013). Based on the results of measurements of total anthocyanin content, "Cam" brown rice contained the maximum anthocyanin after 16 $\mathrm{h}$ sprouting. It can be due to the increase of enzymes activities including the anthocyanin forming enzymes such as PAL (phenylalanine ammonia lyase) enzyme. The result of the study of Yudiono and Kurniawati (2018) suggested that the anthocyanin pigments of the purple sweet potatoes increased after sprouting, was related to the increased PAL enzyme.

Four factors mainly play important roles in the germination process of CBR. Optimum conditions obtained by RSM for anthocyanin enrichment included the following parameters: soaking time: $2.6 \mathrm{hrs}$; soaking $\mathrm{pH}$ : 3.1 ; germination time: $15.5 \mathrm{hrs}$ and germination temperature: $34.2^{\circ} \mathrm{C}$.

Table 1 shows the analysis of variance (ANOVA) for the regression equation. The linear term and quadratic term were highly significant $(p<0.01)$. In this case, eleven effects $\left(\mathrm{X}_{1}, \mathrm{X}_{2}, \mathrm{X}_{3}, \mathrm{X}_{4}, \mathrm{X}_{1} \mathrm{X}_{3}, \mathrm{X}_{1} \mathrm{X}_{4} \mathrm{X}_{2} \mathrm{X}_{3}\right.$, $\mathrm{X}_{1}^{2}, \mathrm{X}_{2}^{2}, \mathrm{X}_{3}{ }^{2}$ and $\mathrm{X}_{4}^{2}$ ) have $\mathrm{p}$-values less than 0.05 , indicating that they are significantly different from zero at the $95.0 \%$ confidence level and 3 effects $\left(X_{1} X_{2}, X_{2} X_{4}\right.$, $\mathrm{X}_{3} \mathrm{X}_{4}$ ) have $\mathrm{p}$-values more than 0.05 . The coefficient of correlation $\left(R^{2}\right)$ was $92,9 \%$, showing good fitness of the model. Le Man et al. (2010) and Chauhan and Gupta (2004) have emphasized the acceptance of any model with $R^{2}>0.75$. In addition, the adjusted $\mathrm{R}^{2}$ statistic, which is more suitable for comparing models with different numbers of independent variables, is $91.4 \%$.

This pane displays the regression equation which had been fitted to the data. The predicted second-order polynomial model for the anthocyanin yield $\left(\mathrm{Y}_{1}\right)$ fitted in terms of actual factors was shown in Equation (1)

$$
Y_{1}=-368.4-7.0 X_{1}+24.3 X_{2}+2.6 X_{3}+21.3 X_{4}-1.7 X_{1}^{2}+0.12 X_{1}
$$$$
+0.4 X_{1} X_{4}+4.4 X_{2}^{2}+0.2 X_{2} X_{3}-0.11 X_{3}^{2}-0.3 X_{4}^{2}
$$

Where $Y_{1}$ is anthocyanin content; $X_{1}$ is soaking time; $X_{-2}$ is soaking $\mathrm{pH} ; X_{3}$ is germination time; and $X_{4}$ is germination temperature. 
Table 1. ANOVA for regression equation

\begin{tabular}{lccccc}
\hline \multicolumn{1}{c}{ Source } & Sum of Squares & Df & Mean Square & F-Ratio & p-Value \\
\hline$X_{1}:$ Soaking time & 37.5769 & 1 & 37.5769 & 69.52 & 0 \\
$X_{-2}: \mathrm{pH}$ & 29.7207 & 1 & 29.7207 & 54.99 & 0 \\
$X_{3}:$ Germination time & 5.58534 & 1 & 5.58534 & 10.33 & 0.002 \\
$X_{4}$ : Germination temperature & 28.569 & 1 & 28.569 & 52.86 & 0 \\
$X_{1} X_{1}$ & 44.6818 & 1 & 44.6818 & 82.67 & 0 \\
$X_{1} X_{-2} X_{1} X_{2}$ & 1.21603 & 1 & 1.21603 & 2.25 & 0.1385 \\
$X_{1} X_{3}$ & 2.92053 & 1 & 2.92053 & 5.4 & 0.0233 \\
$X_{1} X_{4}$ & 12.04 & 1 & 12.04 & 22.28 & 0 \\
$X_{-2} X_{-2}$ & 316.109 & 1 & 316.109 & 584.85 & 0 \\
$X_{-2} X_{3}$ & 8.01968 & 1 & 8.01968 & 14.84 & 0.0003 \\
$X_{-2} X_{4}$ & 0.963333 & 1 & 0.963333 & 1.78 & 0.1866 \\
$X_{3} X_{3}$ & 55.5687 & 1 & 55.5687 & 102.81 & 0 \\
$X_{3} X_{4}$ & 0.935208 & 1 & 0.935208 & 1.73 & 0.1931 \\
$X_{4} X_{4}$ & 66.7943 & 1 & 66.7943 & 123.58 & 0 \\
$\mathrm{R}^{2}=92,9 \% ; \mathrm{R}^{2}$ (adjusted for d.f.) $=91.4 \%$. & & & & \\
\hline
\end{tabular}

$X_{1}$, soaking time; $X_{2}$, soaking $\mathrm{pH} ; X_{3}$, germination time; $X_{4}$, germination temperature; Df, degree of freedom.

\subsection{Anthocyanin control chart of the optimized germinated "Cam" brown rice}

This procedure created an individual anthocyanin control chart of the optimized germinated "Cam" brown rice (OGCBR). The control chart was constructed under the assumption that the data came from a normal distribution with a mean equal to 40.3 and a standard deviation equal to 2.6 (Figure 3). Of the 81 non-excluded points shown on the charts, no point was beyond the control limits on the chart. The process was in a state of statistical control at the $95 \%$ confidence level.

Figure 3 indicates that a process was stable and in control. This would be sufficient for the stability portion of a process in the future to achieve high anthocyanin content of GCBR.

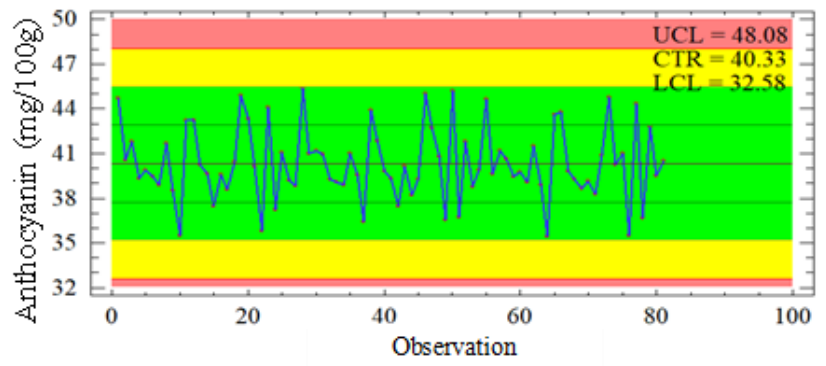

Figure 3. Anthocyanin control chart of the OGCBR. UCL, Upper Control Limit; LCL, Lower Control Limit; CTR, Centerline.

\subsection{Nutritional components of optimized germinated} "Cam" brown rice

During germination, the chemical compositions of rice change drastically, due to the biochemical activity produces essential compounds and energy, for the formation of seedling (Moongngarm and Saetung, 2010).
At the time of germination, huge amounts of nutrients are prepared for the growth of sprout. The birth of the sprout activated all the dormant enzymes in the rice in order to supply the sprout with the best nutrition (Islam and Becerra, 2011). The effects of soaking and germination conditions on $\gamma$-aminobutyric acid (GABA), polyphenol concentration, the percentage of protein, lipid, reducing sugar and starch of OGCBR were described in Figures 4 and 5.

GABA, a four-carbon non-protein amino acid, which is an inhibitory neurotransmitter that has the following benefits: promotes fat loss by the stimulation of the production of human growth hormone; increases the sleep cycle giving deeper rest; boosts the immune system; lowers blood pressure; inhibits development of cancer cells; assists the treatment of anxiety disorders (Patil and Khan, 2011). GABA dramatically increases during sprouting. CBR showed $2.71 \mathrm{mg} / 100 \mathrm{~g}$ GABA content, which increased 7 folds after germination (19.0 $\mathrm{mg} / 100 \mathrm{~g}$ ). It is known that the development of GABA content depends on rice varieties. MRQ74, one of the black rice cultivars, recorded with $0.44 \mathrm{mg} / \mathrm{g}$ of rice of GABA, whereas another black rice cultivar, namely, MR232, showed only $0.03 \mathrm{mg} / \mathrm{g}$ of rice of GABA (Roohinejad et al., 2011). These results were similar to the study of Le Nguyen Doan Duy and Nguyen Cong Ha (2014), $\mathrm{pH}$ values of soaking solution of $\mathrm{pH} 3$ for IR 50404 were optimal for production of GABA (70.3 $\mathrm{mg} / 100 \mathrm{~g})$.

Figure 4 shows the contents of polyphenol in GCBR under different conditions. The temperature and time are key factors in promoting the polyphenol. The results indicated that the optimum germination conditions were to achieve high polyphenol content $65.9 \mathrm{mg} \mathrm{GAE} / 100 \mathrm{~g}$ 


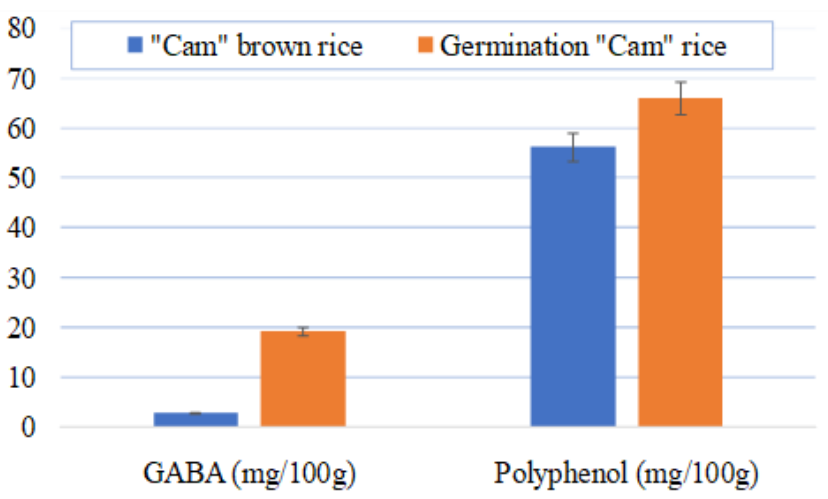

Figure 4. Bioactive components of CBR and OGCBR. CBR, "Cam" Brown rice; OGCBR, optimized germinated "Cam" Brown rice.

- increase 17\% compared with un-GCBR. Polyphenol content increases after germination due to the activities of antioxidants increases the free radicals lead to disruption of the cells releasing the phenolic compounds (Ti et al., 2015). The highest amount of total polyphenol (31.39 $\mathrm{mg} / 100 \mathrm{~g}$ ) was found under anaerobic conditions in germination of "Một bụi đỏ" rice variety (Pham Quang Trung and Nguyen Cong Ha, 2016).

The results from Figure 5 showed that the protein of GCBR increased from $9.1 \%$ to $10.4 \%$, but lipid content decreased from the initial material $3.1 \%$ to final product $2.7 \%$. These results agreed with reports of Pham Quang Trung and Nguyen Cong Ha (2016). Germinated OM2517 showed the highest protein levels in anaerobic conditions (7.78\%). Parnsakhorn and Langkapin (2013) reported that most of the rice lipids are concentrated around the bran layer; thus, these lipids make contact with lipases and thereby hydrolysis may take place to form free fatty acids. During soaking and germination of brown rice, lipid metabolism makes the protein content increases, besides a number of biologically active substances are synthesized as amino acids (Chiang and Yel, 2002). When water absorption, glutamate decarboxylase (GAD) in brown rice is activated and converts glutamic acid into GABA. Glutamic acid is an amino acid presents as stored proteins in brown rice and is changed into a transportation form of amide (Komatsuzaki et al., 2007).

During germination, starch content decreased, so reducing sugar increased (Chandrasekar and Arasaratnam, 2012). Before germination, rice contained a great amount of starch but only small amount of reducing sugar. A content of reducing sugar $2.1 \%$ increased up to $22 \%$ but starch decreased $8 \%$ during the optimization of GCBR. A similar observation was reported in germinated brown rice of Moongngarm (2010). Reducing sugar was found to increase with steeping and germination time due to the hydrolysis of starch. In addition, free fatty acids (FFAs) can then be



Figure 5. Chemical components of CBR and OGCBR. CBR, "Cam" Brown rice; OGCBR, optimized germinated "Cam" Brown rice.

degraded through the $\beta$-oxidation and glyoxylate cycles and subsequently converted into sugars (Graham, 2008).

\subsection{Sensory quality comparison}

Table 2 tabulates the sensory evaluation of unGCBR and OGCBR performed by trained panelists using a quantitative descriptive scale of five points for each indicator.

Table 2. Sensory evaluation results of CBR and OGCBR

\begin{tabular}{ccccc}
\hline & \multicolumn{4}{c}{ Sensory scores } \\
\cline { 2 - 5 } & Color & Aroma & Taste & Texture \\
\hline CBR & $4.56^{\mathrm{a}}$ & $4.71^{\mathrm{a}}$ & $3.81^{\mathrm{b}}$ & $3.59^{\mathrm{b}}$ \\
OGCBR & $4.44^{\mathrm{a}}$ & $4.74^{\mathrm{a}}$ & $4.74^{\mathrm{a}}$ & $4.85^{\mathrm{a}}$ \\
CV $(\%)$ & & & 4.97 & 4.33 \\
\hline
\end{tabular}

CBR, "Cam" brown rice; OGCBR, Optimized germinated "Cam" brown rice, CV (\%), coefficient of variation. Values with different superscripts in each row are significantly 0.01 level.

There was no significant difference between the unGCBR and OGCBR in terms of color and aroma. The taste and texture of the OGCBR were better than un GCBR product. In addition, the coefficient of variation (CV) was $4.97 \%$, and $4.33 \%$. The CV relates the standard deviation of the estimate to the value of this estimate. The value of the coefficient of variation was very low, so the estimate was more precise. This could be due to changes in germinating rice in which amylases catalyze the hydrolysis of starch, stored as amylose and amylopectin, to simple sugars, i.e., the reducing sugars glucose and maltose (Aoki et al., 2006). Choi et al. (2006) reported that the increased amounts of these nutrients relative to those in the un-GCBR were 3.4 times for fructose, 2.75 times for reducing sugars. Tian et al. (2004) explained that the increase in the amount of free form phenolics in germinated brown rice is due to the decomposition of the cell wall during germination. OGCBR over the problem which can be cooked in an ordinary rice cooker and is soft enough to chew even for children. Generally, samples OGCBR had higher quality 
and sensory values than the CBR samples.

\section{Conclusion}

Response surface methodology was successfully applied for obtaining the highest total anthocyanin content for GCBR. The optimum conditions were: soaking time 2.6 hrs; soaking $\mathrm{pH} 3.1$; germination temperature and time of $34.2^{\circ} \mathrm{C}$ and $15.5 \mathrm{hrs}$ respectively. The control chart process in the future to achieve high anthocyanin of GCBR will be stable and controlled. The application of the optimum germination conditions will be promising for the development of novel anthocyanin-rich products and promoting of the consumption of traditional rice.

\section{Conflict of Interest}

The authors declare no conflict of interest.

\section{Acknowledgement}

The research work was funded by Tien Giang university, Viet Nam.

\section{References}

Aoki, N., Scofield, G.N., Wang, X.D., Offler, C.E., Patrick, J.W. and Furbank, R.T. (2006). Pathway of sugar transport in germinating wheat seeds. Plant Physiology, 141(4), 1255-1263. https:// doi.org/10.1104/pp.106.082719

AOAC. (2010). Official methods of analysis. $15^{\text {th }} \mathrm{ed}$. Washington, D.C., USA: Association of Official Analytical Chemists.

Banchuen, J., Paiboon, T., Buncha, O., Phaisan, W. and Piyarat, S. (2010). Increasing the bio-active compounds contents by optimizing the germination conditions of Southern Thai Brown rice. Songklanakarin Science and Technology, 32(3), 219230.

Chaiyasut, C., Bhagavathi, S.S., Noppawat, P., Manee, S.P.K., Sasithorn, S., Pranom, F., Korawee, J., Suchanat, K. and Sartjin P. (2017). Optimization of conditions to achieve high content of gamma amino butyric acid in germinated black rice, and changes in bioactivities. Food Science and Technology, 37(1), $318-326 . \quad$ https:// doi.org/10.1590/1678-457x.33416

Chandrasekar, K. and Arasaratnam, V. (2012). Changes in carbohydrates and amylolytic activity during malting of a local variety of rice. Vingnanam Journal of Science, 1(1), 1-11. https://doi.org/10.4038/ vingnanam.v11i1.4110

Chaudhary, R.C. (2003). Speciality rices of the world: Effect of WTO and IPR on its production trend and marketing. Food Agriculture and Environment, 1(2), 34-41.

Chauhan B. and Gupta R. (2004). Application of statistical experimental design for optimization of alkaline protease production from Bacillus sp. RGR14. Process Biochemistry, 39(12), 2115-2122. https://doi.org/10.1016/j.procbio.2003.11.002

Chen, P.N., Kuo, W.H., Chiang, C.L., Chiou, H.L., Hsieh, Y.S. and Chu, S.C. (2006). Black rice anthocyanin inhibit cancer cells invasion via repressions of MMPs and uPA expression. ChemicoBiological Interactions, 163(3), 218-229. https:// doi.org/10.1016/j.cbi.2006.08.003

Choi, I., Kim, D., Son, J., Yang, C., Chun, J. and Kim, K. (2006). Physico-chemical properties of giant embryo brown rice (Keunnunbyeo). Agricultural Chemistry and Biotechnology, 49(3), 95-100.

Graham, I.A. (2008). Seed storage oil mobilization. Annual Review of Plant Biology, 59, 115-142. https://doi.org/10.1146/ annurev.arplant.59.032607.092938

Harakotr, B., Bhalang, S., Ratchada, T., Marvin, P. and Kamol, L. (2014). Anthocyanin, phenolics and antioxidant activity changes in purple waxy corn as affected by traditional cooking. Food Chemistry, 164, 510-517. https://doi.org/10.1016/ j.foodchem.2014.05.069

Holm J., Bjorck I., Drews, A. and Asp. N. (1986). A rapid method for the analysis of starch. Starch Starke, 38(7), 224-226. https://doi.org/10.1002/ star.19860380704

Islam, M.A. and Becerra, J.X. (2012). Analysis of chemical components involved in germination process of rice variety Jhapra. Scientific Research, 4(1), 251-262. https://doi.org/10.3329/jsr.v4i1.7598

Kaur, M., Asthir, B. and Mahajan, G. (2017). Variation in antioxidants, bioactive compounds and antioxidant capacity in germinated and ungerminated grains of ten rice cultivars. Rice Science, 24(6), 349359. https://doi.org/10.1016/j.rsci.2017.08.002

Khoo, H.E., Azlan, A., Tang, S.T. and Lim, S.M. (2017). Anthocyanidins and anthocyanin: colored pigments as food, pharmaceutical ingredients, and the potential health benefits. Food and Nutrition Research, 61(1), 1361- $1379 . \quad \mathrm{https} / / /$ doi.org/10.1080/16546628.2017.1361779

Kim, M.K., Kim, H.A., Koh, K., Hee-Seon, K., Lee, Y.S. and Kim, Y.H. (2008). Identification and quantification of anthocyanin pigments in colored rice. Nutrition Research Practice, 2(1), 46-49. https://doi.org/10.4162/nrp.2008.2.1.46

Kim, S.P., Kang, M.Y., Nam, S.H. and Friedman, M. 
(2012). Dietary rice component $\gamma$-oryzanol inhibits tumor growth in tumor-bearing mice. Molecular Nutrition and Food Research, 56(6), 935-944. https://doi.org/10.1002/mnfr.201200057

Kirca, A., Ozkan, M. and Cemeroglu, B. (2007). Effects of temperature, solid content and $\mathrm{pH}$ on the stability of black carrot anthocyanin. Food Chemistry, 101(1), 212-218.

https://doi.org/10.1016/ j.foodchem.2006.01.019

Komatsuzaki, N., Tsukahara, K., Toyoshima, H., Suzuki, T., Shimizu, N. and Kimura T. (2007). Effect of soaking and gaseous treatment on GABA content in germinated brown rice. Food Engineering, 78(2), 556-560.

j.jfoodeng.2005.10.036

Le, N.D.D. and Nguyen, C.H. (2014). Influence of soaking and germination conditions on the $\gamma$ aminobutyric acid (GABA) content of 2 rice varieties (IR 50404 and Jasmine 85) from Mekong Delta. Journal of Science and Development, 12(1), 59-64.

Le Man, H., Behera, S. and Park, H. (2010). Optimization of operational parameters for ethanol production from Korean food waste leachate. International Journal of Environmental Science and Technology, 7(1), 157-164. https:// doi.org/10.1007/BF03326127

Loan, L.T.K. and Thuy, N.M (2019). Study on production process of germinated grains of black rice with high anthocyanin content and good quality. Journal of Agricultural Science and Technology, 6 (103), $44-50$.

.Loan, L.T.K, Thuy N.M. and Thanh, N.V. (2018). Optimization of Formulation of Gluten-Free Rice Bread using Response Surface Methodology. International Journal of Science and Research, 7 (11), 1462-1468. https://doi.org/10.21275/ ART20193012.

Lee, J., Durst, R.W. and Wrolstad R.E. (2005). Determination of total monomeric anthocyanin pigment content of fruit juices, beverages, natural colorants, and wines by the $\mathrm{pH}$ differential method: collaborative study. AOAC International, 88(5), 1269-1278.

Moongngarm, A. and Saetung, N. (2010). Comparison of chemical compositions and bioactive compounds of germinated rough rice and brown rice. Food Chemistry, 122(3), 782-788. ttps://doi.org/10.1016/ j.foodchem.2010.03.053

Moongngarm, A. (2010). Influence of germination conditions on starch, physicochemical properties, and microscopic structure of rice flour. In 2010
International Conference on Biology, Environment and Chemistry, IPCBEE. Vol. 1, p. 78-82. Singapore: IACSIT Press

Nam, S.H., Choi, S.P., Kang, M.Y., Koh, H.J., Kozukue, N. and Friedman, M. (2006). Antioxidative activities of bran from twenty-one pigmented rice cultivars. Food Chemistry, 94, 613-620. https:// doi.org/10.1016/j.foodchem.2004.12.010

Parnsakhorn, S. and Langkapin J. (2013). Changes in physicochemical characteristics of germinated brown rice and brown rice during storage at various temperatures. Agricultural Engineering International, 15(2), 293-303.

Patil, S.B. and Khan, M.K. (2011). Germinated brown rice as a value added rice product: a review. Journal of Food Science and Technology, 48(6), 661-667. https://doi.org/10.1007/s13197-011-0232-4

Pengkumsri, N., Chaiyasut, C., Saenjum, C., Sirilun, S., Sartjin, P., Prasit, S., Sophon, S. and Bhagavathi, S. S. (2015). Physicochemical and antioxidative properties of black, brown and red rice varieties of northern Thailand. Food Science and Technology Campinas, 35(2), 331-338. https:// doi.org/10.1590/1678-457X.6573

Roobha, J.J., Saravanakumar, M., Aravindhan, K.M. and Suganya Devi, P. (2011). The effect of light, temperature, $\mathrm{pH}$ on stability of anthocyanin pigments in Musa acuminata bract. Research in Plant Biology, 1(5), 05-12.

Roohinejad, S., Omidizadeh, A., Mirhosseini, H., Saari, N., Mustafa, S., Mohd Yusof, R., Meor Hussin, A.S., Hamid, A. and Abd Manap, M.Y. (2010). Effect of pre-germination time of brown rice on serum cholesterol levels of hypercholesterolaemic rats. The Science of Food and Agriculture, 90(2), 245-251. https://doi.org/10.1002/jsfa.3803

Sangsila, A., Promden, W. and Pimda, W. (2018). Antioxidant and antityrosinase activities in germinated brown rice of indigenous Thai cultivars. International Agricultural Technology, 14(7), 18831892.

Somogyi, M. (1952). Notes on sugar determination. Journal of Biological Chemistry, 195, 19-23.

Soxhlet, F. (1879). Die gewichtsanalytische Bestimmung des Milchfettes. Dingler's Polytechnisches Journal, 232, 461-465. [In German].

Sutharut, J. and Sudarat, J. (2012). Total anthocyanin content and antioxidant activity of germinated colored rice. International Food Research Journal, 19(1), 215221.

Thuengtung, S., Niwat, C., Tamura, M. and Ogawa, Y. (2018). In vitro examination of starch digestibility 
and changes in antioxidant activities of selected cooked pigmented rice. Food Bioscience, 23, 129136. https://doi.org/10.1016/j.fbio.2017.12.014

Ti, H., Zhang, R., Zhang, M., Wei, Z., Chi, J., Deng, Y. and Zhang, Y. (2015). Effect of extrusion on phytochemical profiles in milled fraction of black rice. Food Chemistry, 178, 186-194. https:// doi.org/10.1016/j.foodchem.2015.01.087

Tian, S., Nakamura, K. and Kayahara, H. (2004). Analysis of phenolic compounds in white rice, brown rice and germinated brown rice. Journal of Agricultural and Food Chemistry, 52, 4808-4813. https://doi.org/10.1021/jf049446f

Trachoo, N., Boudreaux, C., Moongngarm, A., Samappito, S. and Gaensakoo, R. (2006). Effect of germinated rough rice media on growth of selected probiotic bacteria. Pakistan Journal of Biological Sciences, 9(14), 2657-2661. https://doi.org/10.3923/ pjbs.2006.2657.2661

Tsuda, T., Horio, F. and Osawa, T. (2002). Cyanidin 3-O - $\beta$-glucoside suppresses nitric oxide production during a zymosan treatment in rats. Journal of Nutritional Science and Vitaminology, 48(4), 305315. https://doi.org/10.3177/jnsv.48.305

Turturică, M., Oancea, A.M. and Râpeanu, G. (2015). Anthocyanin: naturally occurring fruit pigments with functional properties. Food Technology, 39(1), 9-24.

Umnajkitikorn, K., Bualang, F. and Kobkiat, S. (2013). Enhancing antioxidant properties of germinate Thai rice (Oryza sativa L.) cv. Kum Doi Saket with salinity. Rice Research, 1(1), 1-8. https:// doi.org/10.3177/jnsv.48.305

Wu, F.F., Yang, N., Toure, A., Jin, Z.Y. and Xu, X.M. (2013). Germinated brown rice and its role in human health. Critical reviews in Food Science and Nutrition, 53(5), 451-463. https:// doi.org/10.1080/10408398.2010.542259

You-Tung, L., Cheng-Cheng, P., Shwu-Tzy, W., and Chi-Yue, C. (2015). Effect of different germination conditions on antioxidative properties and bioactive compounds of germinated brown rice. BioMed Research International, 2015, 1-10. https:// doi.org/10.1155/2015/608761

Yudiono, K. and Kurniawati, L. (2018). Effect of sprouting on anthocyanin, antioxidant activity, color intensity and color attributes in purple sweet potatoes. Food Research, 2(2), 171 - 176. https:// doi.org/10.26656/fr.2017.2(2).252

Zhao, C., Giusti, M.M., Malik, M., Moyer M.P. and Magnuson B.A. (2004). Effects of commercial anthocyanin-rich extracts on colonic cancer and nontumorigenic colonic cell growth. Journal of
Agricultural and Food Chemistry, 52, 61226128. https://doi.org/10.1021/jf049517a 